\title{
To Evaluate the Application of Alkoxide Sol-Gel Method in Fabrication of 3YSZ-MWCNTs Nanocomposites, in an Attempt to Improve Its Mechanical Properties
}

\author{
Ali Ahmadi, ${ }^{1,2}$ Amir Ali Youzbashi, ${ }^{1}$ Ahmad Nozad Golikand, \\ Toraj Ebadzadeh, ${ }^{1}$ and Amir Maghsoudipour ${ }^{1}$ \\ ${ }^{1}$ Materials and Energy Research Centre, P.O. Box 31878-316, Karaj 31787-316, Iran \\ ${ }^{2}$ Materials Research School, NSTRI, P.O. Box 81465-1589, Isfahan 8166184111, Iran \\ Correspondence should be addressed to Amir Ali Youzbashi; a-yuzbashi@merc.ac.ir
}

Received 26 April 2014; Revised 5 August 2014; Accepted 20 August 2014; Published 12 October 2014

Academic Editor: Claude Estournès

Copyright (C) 2014 Ali Ahmadi et al. This is an open access article distributed under the Creative Commons Attribution License, which permits unrestricted use, distribution, and reproduction in any medium, provided the original work is properly cited.

In the present research work, fabrication of YSZ-CNTs composite system through alkoxide sol-gel processing was evaluated, in an attempt to improve its mechanical properties. Nanocomposites containing $0.5-2 \mathrm{wt} \%$ MWCNTs were then fabricated through the hydrolysis and condensation processing of the solution mixtures containing alkoxide and inorganic precursors along with the functionalized CNTs under basic condition and its final sintering by the SPS technique at $1400^{\circ} \mathrm{C}$. Results showed the formation of a nanocomposite powder based on pure 3YSZ matrix, with well dispersion of CNTs and its good adhesion to the matrix particles in composite containing $0.5 \mathrm{wt} \%$ CNTs. The fracture toughness of sintered samples showed around $24 \%$ increase for the composite containing $0.5 \mathrm{wt} \%$ CNTs. The fracture toughness, hardness, and density decreased due to the agglomeration of CNTs over $0.5 \mathrm{wt} \%$. Toughening mechanisms including pullout and crack bridging were observed on the polished and fractured surfaces.

\section{Introduction}

Ceramics based on yttria stabilized zirconia have attained much attention, due to their unique mechanical characteristics. However, fracture toughness of these ceramics is not sufficiently good to meet the needs of many high performance ceramics. Therefore, many attempts are being made in order to improve their mechanical properties, mainly, through fabrication of their composites with carbon nanostructures. Among them, carbon nanotubes have shown to be the promising nanoscale materials, which have been widely used in reinforcing of various ceramic materials.

CNTs can improve the mechanical properties of ceramics through the reduction of grain size and toughening mechanism including pull-out, crack bridging, and crack deflection $[1,2]$. For successful development of CNT/composite materials, besides the uniformity in composition, structure, particle size, and shape of the synthesized matrix nanopowder as the effective structural characteristics, a number of the key factors, concerning CNTs, must be challenged. CNTs must be processed in such a way as to ensure its homogeneous dispersion within the ceramic matrix, whilst developing an appropriate degree of interfacial bonding [3] .

No doubt, the above structural requirements could be fulfilled through proper selection of the techniques, during the synthesis of the composite powder, as well as its sintering process. Although, some researchers have attempted to fabricate the $\mathrm{ZrO}_{2}$-CNT composite by various methods, the observed mechanical properties could not be adequately explained on the basis of their structural characteristics, and, in most of the cases, the results show inconsistency. The reason may be due to the complexity of the factors, influencing the structural and mechanical properties of these composites. For instance, Sun et al. [4] and Duszová et al. [5] fabricated 3Y-TZP/MWCNTs composites through colloidal processing route followed by SPS and hot press sintering techniques. Hardness and fracture toughness of the fabricated composites were found to decrease with increasing CNT weight percent. The existence of agglomerated CNTs at 
the grain boundaries and the weak bonding between carbon nanotube and zirconia matrix are cited as the main reasons for the observed failure in reinforcement. On the other hand, Zhou et al. [6] prepared the bulk composites of $3 \mathrm{~mol} \%$ yttria stabilized zirconia ceramics reinforced by $0.5-1.5 \mathrm{wt} \%$ CNTs through colloidal processing. Flexural strength and fracture toughness of composites containing $1 \mathrm{wt} \% \mathrm{CNTs}$ were found to increase up to $8.4 \%$ and $21.1 \%$, respectively. In a similar study, Chintapalli et al. [7] produced high density zirconia-carbon nanotube through planetary ball milling and SPS processes, through addition of relatively small volume fractions of MWCNTs (0-2 vol.\%) to 3 mol\% yttria doped zirconia. The indentation fracture toughness was nearly $15 \%$ higher for the composites containing 2 vol.\% MWCNTs as compared to their monolithic counterparts. Mazaheri et al. [8] mixed YSZ powder with CNTs by attrition milling, followed by a fast SPS, resulting in almost full-dense structure with well-distributed CNTs. Mechanical properties, through determination of Young's modulus, indentation hardness, and fracture toughness of the composites containing CNTs in the range of $0.5-5 \mathrm{wt} \%$, were observed to be significantly improved.

The above presented results, as well as many others, do not give a clear picture about the relation between the observed mechanical properties of $\mathrm{ZrO}_{2}$-CNTs composites and their structural characteristics. Even the suitability of the method to be used for the fabrication of these composites cannot be easily deduced from the literature. For example, the mechanical properties of the composite which was prepared through colloidal processing route [4], as an effective method in synthesis of nanostructured materials, could not be improved as a result of CNTs addition to zirconia matrix, while the same composite which was prepared through the simple attrition milling process surprisingly led to appreciably enhanced mechanical properties [8]. In fact, the inconsistency existing among these results cannot be easily explained and it seems that more careful investigations, considering other effective factors, must be carried out.

However, observation of such contradictions in the above mentioned results cannot disclaim the effectiveness and usefulness of the synthesis methods based on the solution chemistry routes, as, in most of them, the reactants can be homogeneously mixed through the use of suitable precursors, solvents, and also surfactants. Sol-gel method may therefore be considered as the most useful one in providing the desired processing conditions for fabrication of such nanostructured composites like $\mathrm{ZrO}_{2}$-CNTs.

Sol-gel processes have been effectively used to make the ceramic nanocomposite materials containing carbon nanotubes as a reinforcing agent. The intimate mixing of CNTs with the organic and/or inorganic precursors in suitable solvents provides a good dispersion of the CNTs in the inorganic gel network which is formed as a result of the hydrolysis and condensation processes. This advantage along with the porous nature of the gel network would facilitate the encapsulation of carbon nanotubes by the ceramic material nanoparticles, which consequently can result in their better interaction. For instance, Mo et al. [9] fabricated carbon nanotube reinforced alumina matrix nanocomposite, Ning et al. [10] and de Andrade et al. [11] fabricated $\mathrm{SiO}_{2}$-CNT composites by sol-gel process and results showed improvement in mechanical properties.

Only few studies on $\mathrm{ZrO}_{2} / \mathrm{CNTs}$ composites have been reported where most of them have mainly addressed the dispersion of CNTs within the matrix by the use of various surfactants, without considering the mechanical properties of the bulk materials. For instance, Silva et al. [12] used a surfactant called dabcosil stearate as dispersant in preparation of stabilized suspension of MWCNTs, for preparation of MWCNT/zirconium and MWCNT/alumina composites through sol-gel process. Also, Almeida et al. [13] prepared MWCNT/zirconium composites by sol-gel method using sodium and ammonium stearate as dispersing agents. The results showed a proper dispersion and the MWCNTs were fully coated by the matrix material, indicating a very good adherence. These studies along with many other ones clearly express the importance of solution based processes in facilitating the dispersion of CNTs within the matrix materials and also the formation of a strong interfacial bonding between them.

In order to elucidate the relation between the observed structural and mechanical properties of $\mathrm{ZrO}_{2}$-CNTs and the synthesis method, the fabrication of $\mathrm{ZrO}_{2}$-MWCNTs nanocomposite system through alkoxide sol-gel route was evaluated. Also, in order to reduce the risk of CNTs damage and preserve its bonding with $\mathrm{ZrO}_{2}$ matrix, as well as to obtain highly dense material, SPS sintering technique was used.

\section{Experimental Procedure}

2.1. Materials. The chemical components and precursors used in this study include multiwalled CNTs (Chingdu, China) with 1-10 $\mu \mathrm{m}$ length, $<50 \mathrm{~nm}$ diameter, and purity over $95 \%$, zirconium propoxide (70 wt\% in 1-propanol, Sigma-Aldrich), yttrium nitrate (III) hexahydrate (99.8\%, Sigma-Aldrich), propanol (99.8\%, Merck), and ammonia solution (25\%, Merck).

\subsection{Methods}

2.2.1. Functionalization of MWCNTs. MWCNTs were immersed in $\mathrm{H}_{2} \mathrm{SO}_{4} / \mathrm{HNO}_{3}(3: 1)$ solution at room temperature and treated in an ultrasonic bath $(100 \mathrm{~W}, 40 \mathrm{Kh})$ for $0.5 \mathrm{~h}$. The functionalization treatment was completed after holding for $15 \mathrm{~h}$. The solution was then filtered through a $0.2 \mu \mathrm{m}$ cellulose acetate membrane. The MWCNTs were washed several times using distilled water until the $\mathrm{pH}$ of the wash solutions reaches to about 5.5 [14]. Filtered MWCNTs were dried at $75^{\circ} \mathrm{C}$ for $24 \mathrm{~h}$.

\subsubsection{Preparation of $\mathrm{ZrO}_{2} / M W C N T$ Nanocomposite Powders.} The procedure used for the preparation of the nanocomposite powders is schematically presented in Figure 1. The molar ratio of zirconium alkoxide to propanol was taken as $1: 80$. Initially, $0.475 \mathrm{gr}$ of yttrium nitrate was dissolved in $35 \mathrm{~mL}$ of propanol and stirred for $10 \mathrm{~min}$; then $9 \mathrm{~mL}$ of zirconium alkoxide was added and stirring continued for another $30 \mathrm{~min}$. The certain amounts of CNTs were added to $80 \mathrm{~mL}$ 


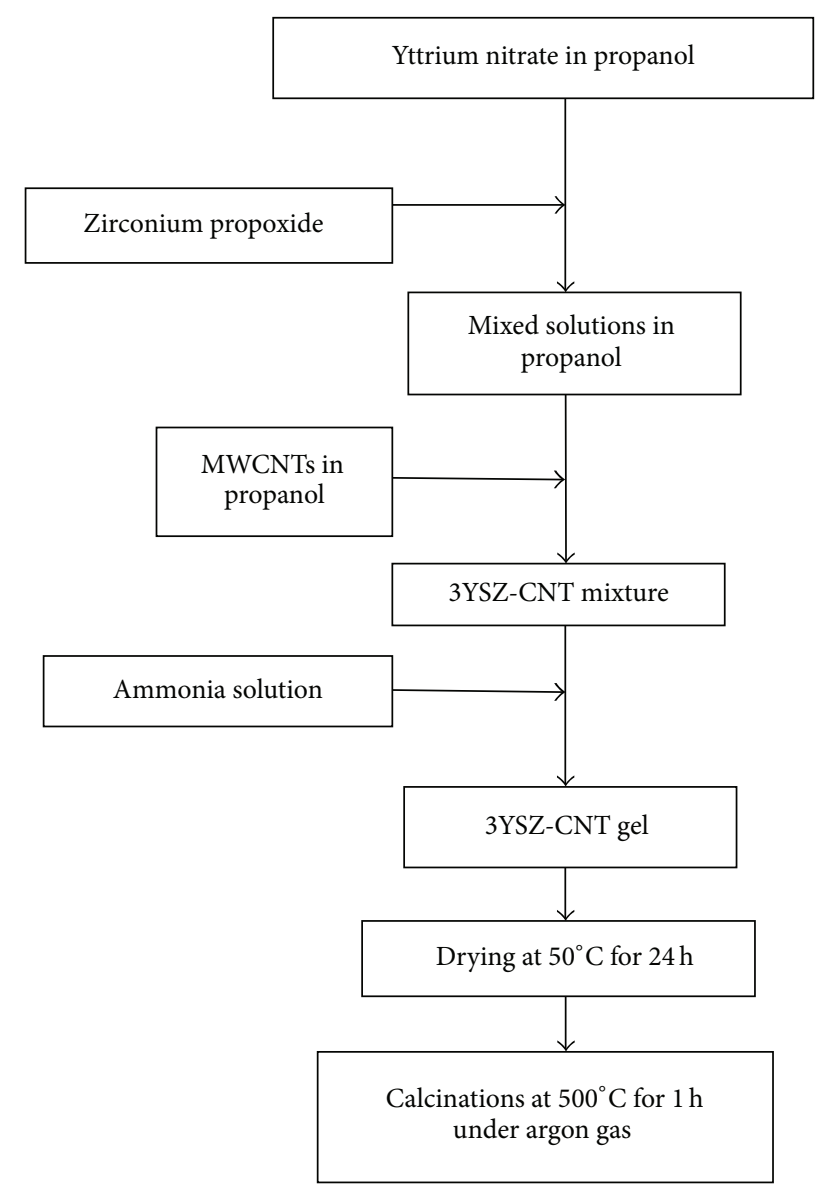

Figure 1: Procedure for the preparation of the 3YSZ-MWCNT nanocomposite powders.

of propanol and sonicated for $0.5-1 \mathrm{~h}$ until the agglomerates were separated. The carbon nanotube suspension was added to the solutions in propanol and, finally, $8 \mathrm{~mL}$ of ammonia solution was dripped, in order to induce the hydrolysis and condensation processes, necessary for the completion of the sol-gel process. The sol-gel product was dried at $50^{\circ} \mathrm{C}$ for 24 hours and then crushed in a mortar, after which it was calcined at $500^{\circ} \mathrm{C}$ for $2 \mathrm{~h}$ under argon atmosphere.

2.2.3. Densification Process. Spark plasma sintering process reduces the risk of carbon nanotube damage, owing to the low sintering temperature and short sintering time, which can result in obtaining the full-dense nanocomposites. Sintering of YSZ powder and its composites with $0.5,1$, and $2 \mathrm{wt} \%$ CNTs was then carried out by SPS technique under vacuum $(10 \mathrm{~Pa})$ at temperature of $1400^{\circ} \mathrm{C}$, heating rate of $50^{\circ} \mathrm{C} / \mathrm{min}$, and maximum applied pressure of $25 \mathrm{MPa}$ with a soaking time of 5 minutes. Diameter and thickness of the consolidated samples were $13 \mathrm{~mm}$ and $4 \mathrm{~mm}$, respectively. Surfaces of the sintered samples were polished to remove the graphite layer. lands) and FTIR (Perkin elmer, spectrum 800, Germany) were used to monitor the functionalization process of MWCNTs. Raman spectroscopy (HR-800 Jobin-Yvon, with $532 \mathrm{~nm}$ Nd-YAG excitation, China) was used to evaluate MWCNTs damage after functionalization and SPS sintering. Thermal analysis (STA 1500, Rhoemetric Scientific, UK) of the products was carried out under argon atmosphere at a heating rate of $10^{\circ} \mathrm{C} / \mathrm{min}$. The calcined powders were analyzed by XRD (Philips, PW 1800, $\mathrm{Cu} \mathrm{k}_{\alpha}$ ), and FEG-SEM (Hitachi, Japan) and TEM analytical techniques were used to investigate microstructure, phase composition, crystallite/particle size, and distribution of CNTs in the zirconia matrix.

Density of the sintered samples was determined by Archimedes method in distilled water. Theoretical densities of the composite samples were calculated based on the rule of mixtures. Density values of $6.10 \mathrm{~g} \mathrm{~cm}^{-3}$ and $2.0 \mathrm{~g} \mathrm{~cm}^{-3}$ were used for $3 \mathrm{Y}-\mathrm{ZrO}_{2}$ and MWCNTs samples, respectively.

The fracture and polished surfaces of the sintered composites were also studied by SEM. The indentation tests were carried out with a diamond Vickers indenter (Wilson Wolpert, Germany) according to ASTM E92-03 standard method with $20 \mathrm{Kg}$ load and a dwell time of $10 \mathrm{~s}$ on carefully polished surfaces. An average of four indentations was reported for each sample. The hardness (HV) was calculated from the diagonal length of the indentation:

$$
\mathrm{HV}=\frac{1.854 P}{d^{2}}
$$

where $P$ is the applied load and $d$ is the mean value of the diagonal length. The fracture toughness $\left(K_{\mathrm{Ic}}\right)$ was determined by Vickers indenter using Shetty's equation [15]. Consider

$$
K_{\mathrm{Ic}}=0.0889\left(\frac{H P}{4 L}\right)^{0.5},
$$

where $H$ is the Vickers hardness and $L=c-a$, " $c$ " and " $a$ " are the half of crack length and the diagonal length, respectively. It is clear that the hardness measuring technique cannot be used to estimate the absolute values of the fracture toughness. However, for comparing the relative values of the fracture toughens, it can be used as a fast and simple method, according to other studies [4-6].

\section{Results and Discussion}

3.1. Powder Characteristics. The comparison of TEM micrographs of pristine and functionalized MWCNTs presented in Figure 2 indicates that nanotubes have not been appreciably affected by the acid treatment. This is important because excessive fragmentation of nanotubes reduces the reinforcement effect in the matrix.

Figure 3 shows the FTIR spectra of the pristine and functionalized MWCNTs. The absorption peaks appearing in the spectrum of the acid treated carbon nanotubes clearly indicates the formation of certain functional groups. The overlapped peaks in the range of $3000-3500 \mathrm{~cm}^{-1}$ are characteristic of $\mathrm{O}-\mathrm{H}$ bonds which can be related to hydroxyl and carboxylic groups [14]. The peaks in the range of 2810$2960 \mathrm{~cm}^{-1}$ correspond to the $\mathrm{C}-\mathrm{H}$ stretching whose intensities have increased as a result of the defects formed after 


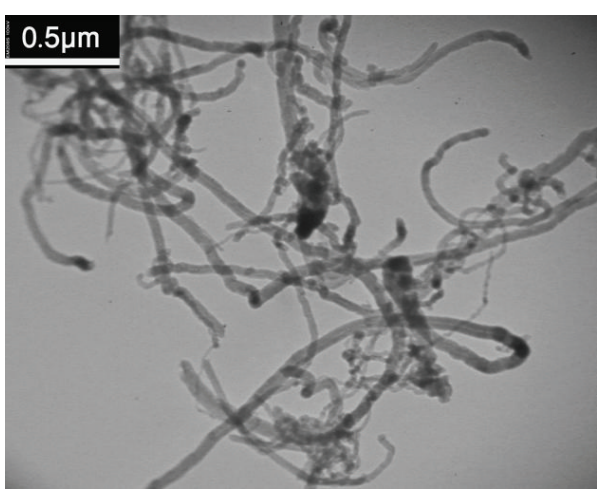

(a)

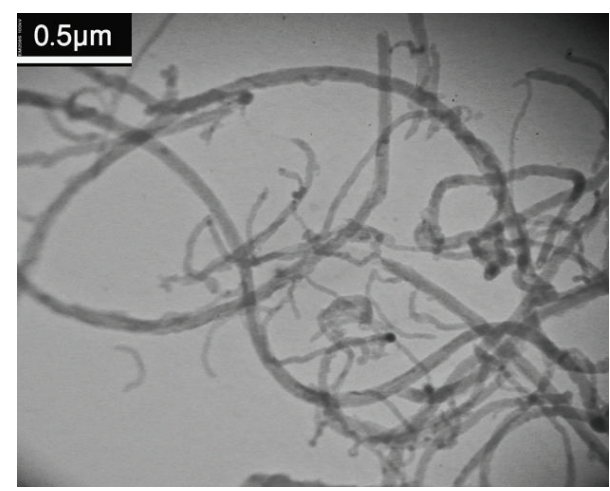

(b)

FIGURE 2: TEM micrographs of MWCNTs (a) before acid treatment and (b) after acid treatment.

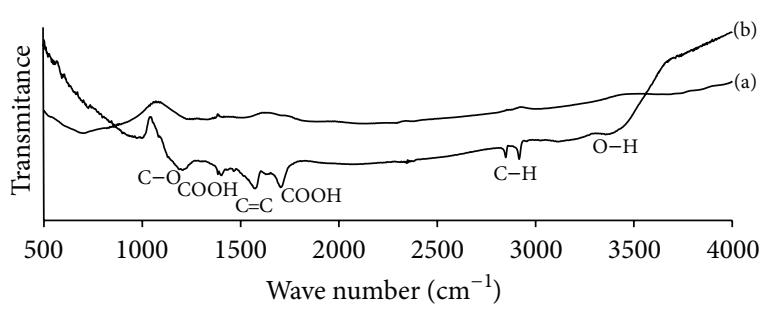

FIGURE 3: FTIR spectra of (a) the pristine and (b) the functionalized MWCNT samples.

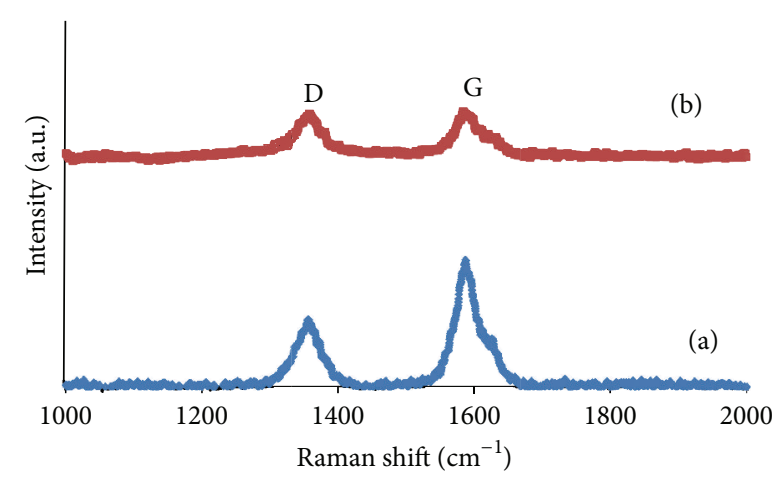

FIgURE 4: Raman spectra of (a) the pristine and (b) the functionalized MWCNT samples.

functionalization process [16]. The peaks at $1730 \mathrm{~cm}^{-1}$ and $1400 \mathrm{~cm}^{-1}$ are related to carboxylic groups $[14,16]$. The peaks at $1600 \mathrm{~cm}^{-1}$ and $1200 \mathrm{~cm}^{-1}$ correspond to the $\mathrm{C}=\mathrm{C}$ and $\mathrm{C}-\mathrm{O}$ bonds, respectively [14].

Figure 4 shows the Raman spectra of pristine and functionalized MWCNTs. The characteristic peaks of CNTs, named as the $\mathrm{D}$ band at $1330 \mathrm{~cm}^{-1}$ and the $\mathrm{G}$ band at $1580 \mathrm{~cm}^{-1}$, can be identified. In the case of the functionalized CNTs, these characteristic peaks can still be identified, indicating that the acid treatment does not appreciably damage the structure of CNTs. However, comparing the ratio $I_{\mathrm{D} / \mathrm{G}}$ values for the functionalized and pristine MWCNTs, it can be observed that the ratio increases for the functionalized

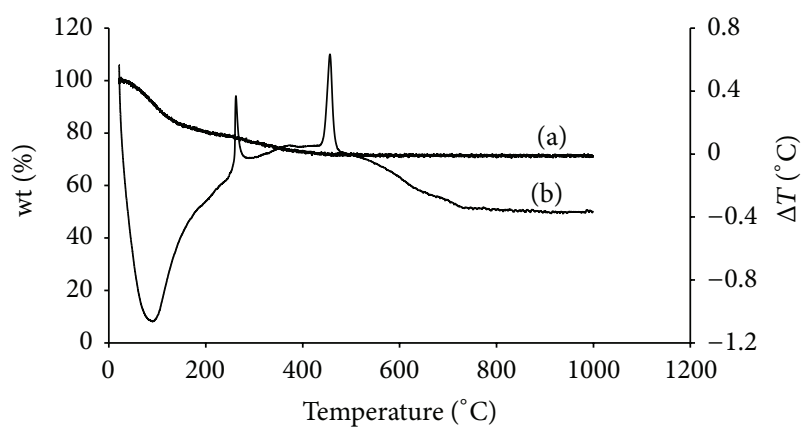

FIGURE 5: Thermal analysis curves of dried nanocomposite gel (a) TGA and (b) DTA.

MWCNTs. This means that the functionalization of CNTs could break some of its bonds and insert chemical groups that can be interpreted as defects on the structure [14].

Figure 5 shows the thermal analytical results of the dried nanocomposite gel. The TGA curve shows two-step weight loss at temperatures of $80^{\circ} \mathrm{C}$ and $280^{\circ} \mathrm{C}$ which are attributed to the removal of alcohol, water, and organic materials. The corresponding endothermic and exothermic peaks for these processes can also be observed. The exothermic peak at $450^{\circ} \mathrm{C}$ is attributed to the tetragonal phase crystallization. Considering the above results, the calcination temperature of $500^{\circ} \mathrm{C}$ was selected for the prepared nanocomposite.

Figure 6 shows the XRD pattern of the calcined nanocomposite powder which reveals the presence of a pure tetragonal stabilized zirconia phase (JCPDS 010-70-7302). Characteristic diffraction peaks associated with CNTs are not observed in this pattern due to the low CNT content in the nanocomposite samples. The average crystallite size of the tetragonal zirconia was determined to be $42 \mathrm{~nm}$, using the Scherer equation.

FEG-SEM and TEM micrographs of $\mathrm{ZrO}_{2}-0.5 \mathrm{wt} \% \mathrm{CNT}$ nanocomposite powder are shown in Figures 7(a) and 7(b), respectively. The microscopic images clearly indicate a homogeneous distribution of MCNTs within the zirconia matrix without significant agglomeration and also a good adhesion between MWCNTs and zirconia nanoparticles. 


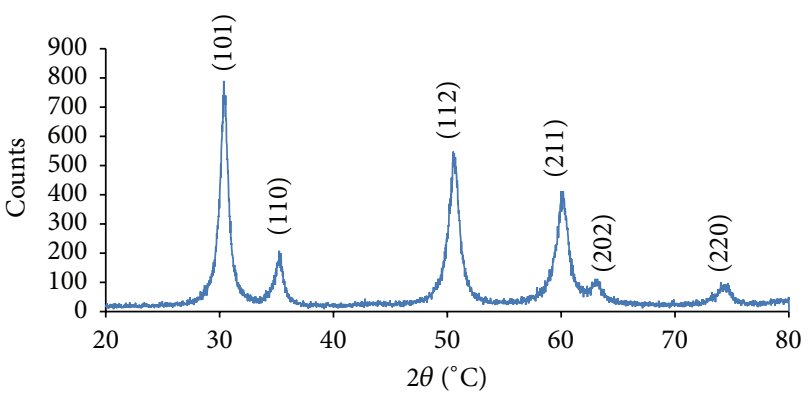

FIGURE 6: X-ray diffraction pattern of the nanocomposite powder, calcined at $500^{\circ} \mathrm{C}$.

3.2. Mechanical Properties. Variations in density, Vickers hardness (HV20), and fracture toughness $\left(K_{\text {Ic }}\right)$ values of the pure 3YTZP and MWCNTs/3YTZP composite samples versus CNTs contents are illustrated in Figures 8 and 9, respectively. It can be observed that, with increase in the amount of carbon nanotubes, the values obtained for density and hardness of the composites undergo a reduction. It is known that the CNTs have a significant role in lowering the ceramics consolidation by restraining the process of pore removal and material transport through grain boundary [17]. A weak interfacial bond between MWCNTs and the matrix also can reduce the hardness, since strong bonding can effectively transfer the load from the matrix to MWCNTs, and then consequently a significant load sharing of MWCNTs improves the hardness of the carbon nanotube/ceramic nanocomposite [18]. However, it can be observed that the nanocomposite containing $0.5 \mathrm{wt} \% \mathrm{CNTs}$ shows about $24 \%$ increase in the fracture toughness value; however, beyond 0.5 wt $\%$ CNTs content, it decreases. This behavior may be due to the fact that agglomeration of CNTs would occur at higher CNTs concentrations resulting in degradation of the mechanical properties.

\subsection{Microstructure of the Fractured Surfaces in the Nanocom-} posites. Figure 10 shows the Raman spectra of the functionalized MWCNTs and fractured surface in the sintered composite reinforced with $2 \mathrm{wt} \%$ MWCNTs. Characteristic Raman peaks of MWCNTs, that is, G and D bands, measured in the sintered composite are nearly identical to those of the functionalized MWCNTs, indicating the presence of nanotubes in the YSZ-MWCNT composites sintered at $1400^{\circ} \mathrm{C}$, with almost the same structural characteristics as in the functionalized MWCNTs $[8,19]$.

SEM images of the fractured surfaces of the sintered samples (Figure 11) indicate the survival of MWCNTs in the nanocomposite after SPS sintering. No significant differences in grain size and fracture mode can be observed in the various consolidated nanocomposite samples. Grain sizes are in the range of $0.2-0.5 \mu \mathrm{m}$ and the fractured surfaces exhibit a combination of transgranular and intergranular fractures in all samples. According to the TEM image shown in Figure 7(b), a good adherence between CNTs and YSZ particles is observed; however the presence of intergranular fractures (Figure 11) indicates a weak interfacial bonding, because strongly bonded CNTs would cause transgranular fracture rather than intergranular fracture, and also at the same time it would inhibit the grain growth leading to a more refined structure [1].

Figure 11(b) shows the fracture surface of the nanocomposite containing $0.5 \mathrm{wt} \%$ MWCNTs. It can be also observed that MWCNTs have constructed bridges between the zirconia grains, a phenomenon which can improve the fracture toughness of the nanocomposite. In contrast, in the case of the nanocomposites with 1 and $2 \mathrm{wt} \%$ MWCNTs (Figures 11(c) and $11(\mathrm{~d})$ ) the examination of the fracture surface shows that MWCNTs were not well dispersed in the zirconia matrix.

In fact, lack of well dispersed MWCNTs prevents their toughening action and may impair reinforcement and structural refining. In Figure 11(c), buckling can be considered as a toughening mechanism in the case of the bent nanotubes which can dissipate the fracture energy and, finally, in Figure 11(d) MWCNT bridging between two zirconia grains can be observed on the fracture surface.

Figure 12 shows the inside of the crack formed as a result of the indentation of the nanocomposite containing $0.5 \mathrm{wt} \% \mathrm{MWCNT}$. The crack bridging along with the broken and pulled out MWCNTs inside the crack can be observed. Bridging by MWCNTs could lower the tensile stress around the crack tips and, therefore, hinders their spreading and dissipates the fracture energy [2]. The high aspect ratio and the enormous specific surface area of the CNTs provide a high potential for toughening through pull out mechanism.

From the results of the present research work, it can be concluded that in spite of CNTs showing apparently homogeneous distribution and good adhesion with zirconia particles and also an acceptable bulk density in composite containing $0.5 \mathrm{wt} \%$ carbon nanotube, it did not result in enhanced mechanical properties. Other researchers have also reported the above behavior $[6,7,9]$ and most of them mentioned that the agglomeration of CNTs was the main cause of the degradation of mechanical properties but other important factors also should be considered. In fact, apart from the homogeneous distribution of CNTs, the nature of the interfacial bonding between the components plays the vital role in providing the appreciably enhanced mechanical properties. However, investigations on the influence of this important factor have been rarely carried out, and, in most of the studies, the improved mechanical properties were related to a good interfacial bonding between the components in the composite, without giving any evidence. Basically, formation of a good interfacial bonding leads to improved mechanical properties for such composites generally depend on the surface structures of the components, especially the reinforcing component, that is, CNTs. Although the intrinsic structural characteristics of CNTs can influence, to a great extent, its capability for the formation of the required composite, there are no much information about it in literatures. In fact, in most of the studies in this area, the used CNTs have not been well characterized, and this may be the main reason for the sporadic results obtained in various investigations concerned with the mechanical properties of the fabricated composites. In fact, selection of an appropriate method for preparation 


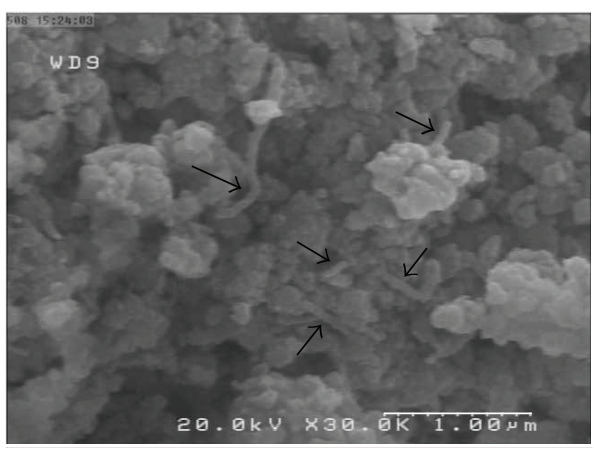

(a)

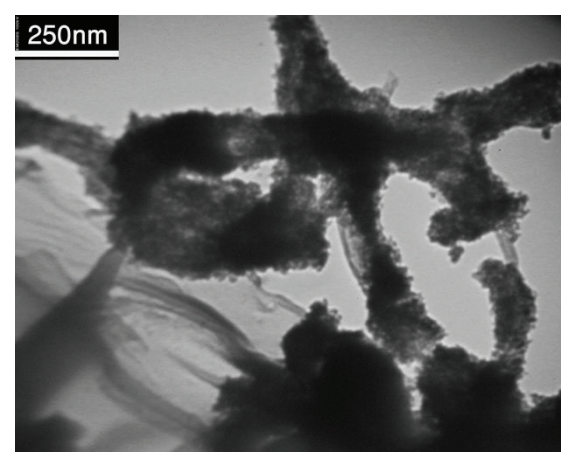

(b)

Figure 7: (a) FEG-SEM and (b) TEM micrographs of $\mathrm{ZrO}_{2}-0.5$ wt $\%$ MWCNT nanocomposite powder (Arrows show the MWCNTs).

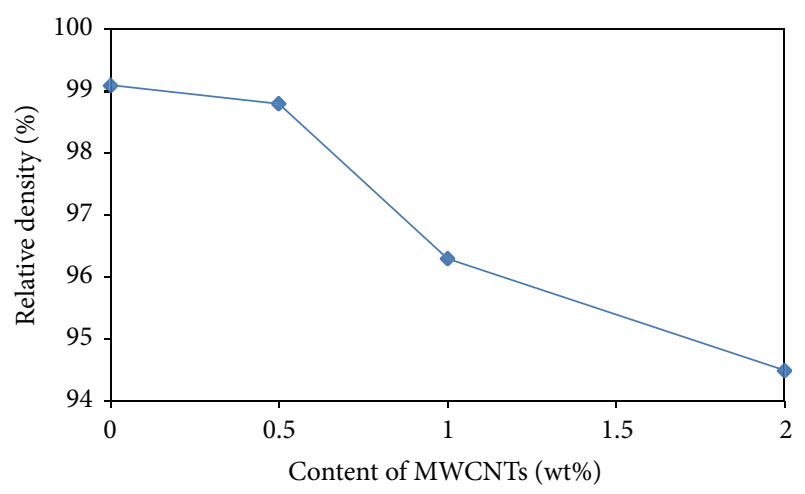

Figure 8: Densities of 3YSZ/MWCNT nanocomposites at different MWCNTs contents.

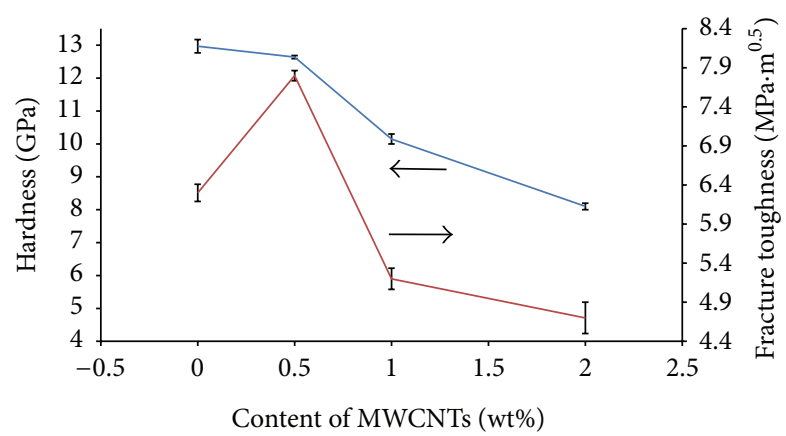

FIGURE 9: Variation in the hardness and fracture toughness values of 3YSZ/MWCNT nanocomposites as a result of increase in MWCNTs content.

of such composites by itself cannot guarantee the desired structural and mechanical properties.

Another important factor which could be responsible in acquiring the improved mechanical properties in these composites is the sintering process. According to the report about one of the rare studies on this topic [8], by using just attrition milling as the only process for the homogenization of the YSZ and CNTs components, application of SPS process could result in the formation of a highly dense $\mathrm{ZrO}_{2}$-CNTs composite with greatly enhanced mechanical properties, for

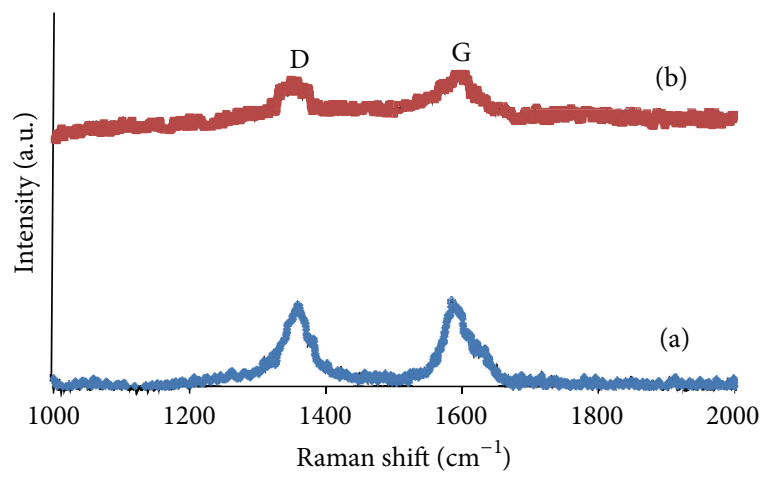

FIGURE 10: Raman spectra of (a) the functionalized MWCNT and (b) sintered composite with $2 \mathrm{wt} \%$ MWCNTs.

the first time. The authors attributed the obtained mechanical properties to the advantages provided by the SPS sintering process including preserving the firm attachment of CNTs to zirconia grains and obtaining fully dense composite. In fact, the authors have not clearly specified the origin of the strong interfacial bonding between zirconia particles and CNTs, and also information about the structural characteristics of the incipient CNTs or details about their processing, if any, was not disclosed. In general, the above discussion clearly indicates the ambiguity in selection of the appropriate method for fabrication of this composite system, due to the inconsistencies observed in the results of the concerned studies, especially those addressing the relation between the observed mechanical properties and the structural characteristics of the fabricated composites. Results obtained in the present research work about applicability of alkoxide sol-gel process as well as the results of many other investigations on this topic, therefore, made us give the following solutions, in order to challenge this controversial topic and end the present contradictions and finally illuminate the way towards fabrication engineering of $\mathrm{ZrO}_{2}$-CNTs composite system.

(1) CNTs to be used for fabrication of these composites should be thoroughly characterized.

(2) Nature of the interfacial bonding between zirconia particles and CNTs, responsible for enhanced 


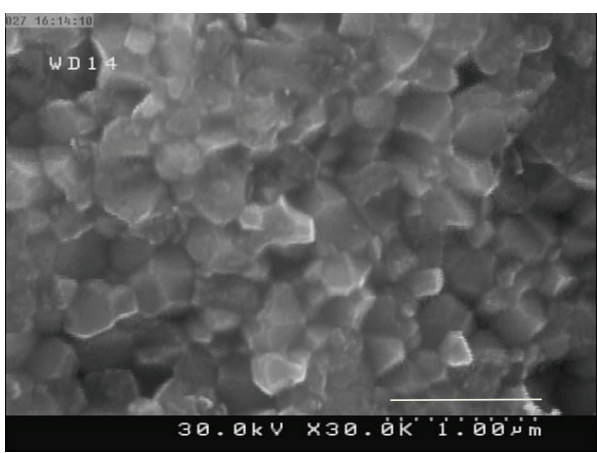

(a)

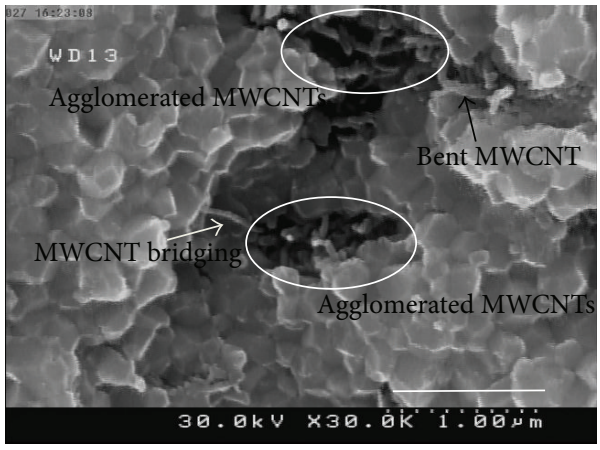

(c)

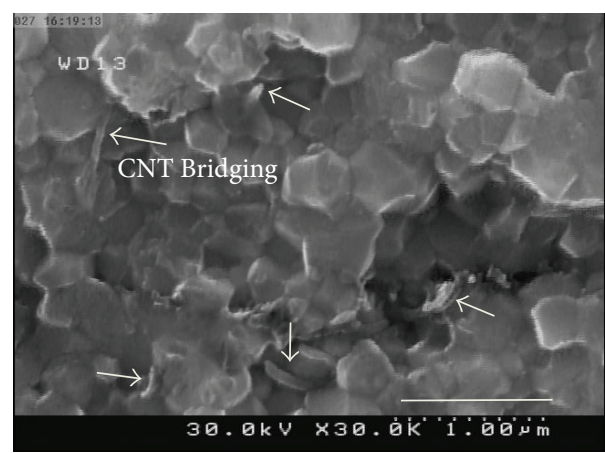

(b)

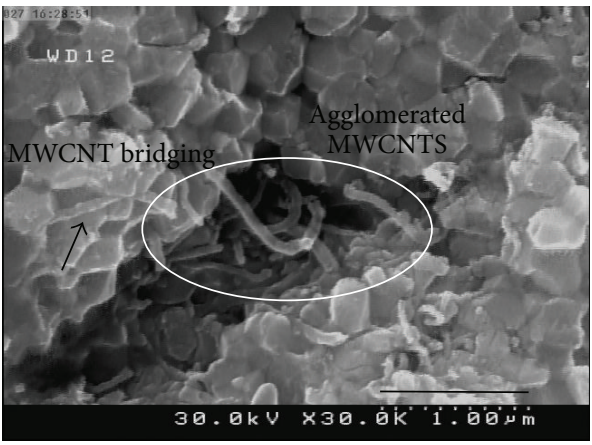

(d)

FIGURE 11: SEM images of fractured surfaces (a) 3Y-TZP, (b) 3Y-TZP+ $0.5 \mathrm{wt} \% \mathrm{MWCNT}$, (c) 3Y-TZP+ $1 \mathrm{wt} \% \mathrm{MWCNT}$, and (d) $3 \mathrm{Y}-\mathrm{TZP}+$ 2 wt $\%$ MWCNT (Arrows show the MWCNTs).

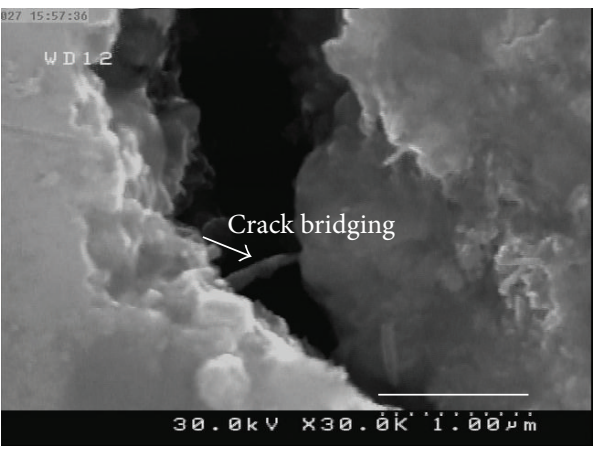

(a)

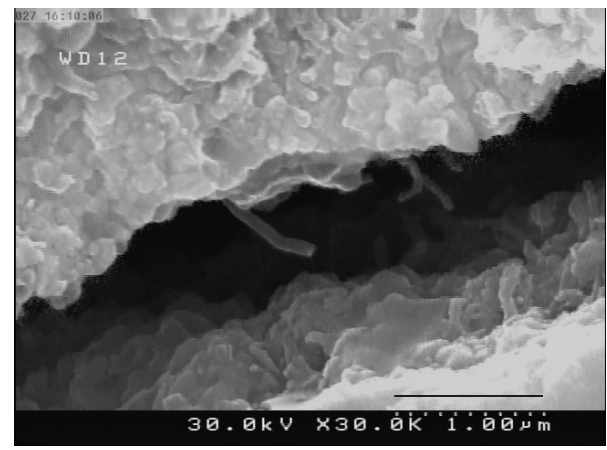

(b)

FIGURE 12: FESEM images of the indentation cracks of nanocomposite with 0.5 wt\% MWCNT (a) crack bridging (b) broken and pulled out MWCNTs.

mechanical properties of these composites, should be carefully identified.

(3) As the strength of the interfacial bonding between zirconia particles and CNTs greatly depends on their surface properties, it seems quite necessary to attempt for identification of their surface species and subsequent appropriate functionalization, specifically in the case of CNTs.

(4) It seems necessary to precisely monitor the processing steps, which are determinant in the formation of the optimum interfacial bonding.
(5) Since fabrication of such nanostructured materials needs more careful engineering, methods based on the solution chemistry should be focused and developed more.

(6) As some of the discrepancies in results may be due to the nonuse of reliable characterization methods, it is strongly suggested to develop more appropriate analytical techniques.

\section{Conclusion}

YSZ-MWCNTs nanocomposite was fabricated through the alkoxide sol-gel and SPS processing routes. Addition of 
MWCNTs resulted in a decrease in density and hardness of the nanocomposites; however, in the case of the composites containing $0.5 \mathrm{wt} \%$ MWCNT, the fracture toughness showed a $24 \%$ increase. By increasing the amount of MWCNTs to up to $2 \mathrm{wt} \%$, the fracture toughness of the composites decreased. The fractography studies showed that the fracture mode does not noticeably undergo a change with addition of MWCNTs. Toughening mechanism was found to take place in all the nanocomposite samples; however, the formation of MWCNTs bundles could decrease the fracture toughness in the nanocomposites containing 1 and $2 \mathrm{wt} \%$ MWCNT. Generally, although solution based methods like sol-gel have shown promising background in effective synthesis of many nanostructured materials, the results of the present investigation showed that the structural characteristics of components, specifically CNTs, seem to be more effective in their reinforcement activity.

\section{Conflict of Interests}

The authors declare that there is no conflict of interests regarding the publication of this paper.

\section{Acknowledgment}

This research work was performed under financial support of materials and energy research center (Grant no. 388974).

\section{References}

[1] I. Ahmad, H. Cao, H. Chen, H. Zhao, A. Kennedy, and Y. Q. Zhu, "Carbon nanotube toughened aluminium oxide nanocomposite," Journal of the European Ceramic Society, vol. 30, no. 4, pp. 865-873, 2010.

[2] M. Estili, A. Kawasaki, H. Sakamoto, Y. Mekuchi, M. Kuno, and T. Tsukada, "The homogeneous dispersion of surfactantless, slightly disordered, crystalline, multiwalled carbon nanotubes in $\alpha$-alumina ceramics for structural reinforcement," Acta Materialia, vol. 56, no. 15, pp. 4070-4079, 2008.

[3] J. Cho, A. R. Boccaccini, and M. S. P. Shaffer, "Ceramic matrix composites containing carbon nanotubes," Journal of Materials Science, vol. 44, no. 8, pp. 1934-1951, 2009.

[4] J. Sun, L. Gao, M. Iwasa, T. Nakayama, and K. Niihara, "Failure investigation of carbon nanotube/3Y-TZP nanocomposites," Ceramics International, vol. 31, no. 8, pp. 1131-1134, 2005.

[5] A. Duszová, J. Dusza, K. Tomášek, G. Blugan, and J. Kuebler, "Microstructure and properties of carbon nanotube/zirconia composite," Journal of the European Ceramic Society, vol. 28, no. 5, pp. 1023-1027, 2008.

[6] J. P. Zhou, Q. M. Gong, K. Y. Yuan et al., "The effects of multiwalled carbon nanotubes on the hot-pressed $3 \mathrm{~mol} \%$ yttria stabilized zirconia ceramics," Materials Science and Engineering A, vol. 520, no. 1-2, pp. 153-157, 2009.

[7] R. K. Chintapalli, F. G. Marro, B. Milsom, M. Reece, and M. Anglada, "Processing and characterization of high-density zirconia-carbon nanotube composites," Materials Science and Engineering A, vol. 549, pp. 50-59, 2012.

[8] M. Mazaheri, D. Mari, R. Schaller, G. Bonnefont, and G. Fantozzi, "Processing of yttria stabilized zirconia reinforced with multi-walled carbon nanotubes with attractive mechanical properties," Journal of the European Ceramic Society, vol. 31, no. 14, pp. 2691-2698, 2011.

[9] C. B. Mo, S. I. Cha, K. T. Kim, K. H. Lee, and S. H. Hong, "Fabrication of carbon nanotube reinforced alumina matrix nanocomposite by sol-gel process," Materials Science and Engineering A, vol. 395, no. 1-2, pp. 124-128, 2005.

[10] J. Ning, J. Zhang, Y. Pan, and J. Guo, "Surfactants assisted processing of carbon nanotube-reinforced $\mathrm{SiO}_{2}$ matrix composites," Ceramics International, vol. 30, no. 1, pp. 63-67, 2004.

[11] M. J. de Andrade, M. D. Lima, C. P. Bergmann et al., "Carbon nanotube/silica composites obtained by sol-gel and highpressure techniques," Nanotechnology, vol. 19, no. 26, Article ID 265607, 2008.

[12] P. R. Silva, V. O. Almeida, G. B. MacHado, E. V. Benvenutti, T. M. H. Costa, and M. R. Gallas, "Surfactant-based dispersant for multiwall carbon nanotubes to prepare ceramic composites by a sol-gel method," Langmuir, vol. 28, no. 2, pp. 1447-1452, 2012.

[13] V. O. Almeida, N. M. Balzaretti, T. M. H. Costa, G. B. Machado, and M. R. Gallas, "Surfactants for CNTs dispersion in zirconiabased ceramic matrix by sol-gel method," Journal of Sol-Gel Science and Technology, vol. 65, no. 2, pp. 143-149, 2013.

[14] A. G. Osorio, I. C. L. Silveira, V. L. Bueno, and C. P. Bergmann, " $\mathrm{H}_{2} \mathrm{SO}_{4} / \mathrm{HNO}_{3} / \mathrm{HCl}$-Functionalization and its effect on dispersion of carbon nanotubes in aqueous media," Applied Surface Science, vol. 255, no. 5, pp. 2485-2489, 2008.

[15] D. K. Shetty, I. G. Wright, P. N. Mincer, and A. H. Clauer, "Indentation fracture of WC-Co cermets," Journal of Materials Science, vol. 20, no. 5, pp. 1873-1882, 1985.

[16] X. H. Men, Z. Z. Zhang, H. J. Song, K. Wang, and W. Jiang, "Functionalization of carbon nanotubes to improve the tribological properties of poly(furfuryl alcohol) composite coatings," Composites Science and Technology, vol. 68, no. 3-4, pp. 10421049, 2008.

[17] S. Sarkar and P. K. Das, "Microstructure and physicomechanical properties of pressureless sintered multiwalled carbon nanotube/alumina nanocomposites," Journal of Ceramics International, vol. 38, no. 1, pp. 423-432, 2012.

[18] S. I. Cha, K. T. Kim, K. H. Lee, C. B. Mo, and S. H. Hong, "Strengthening and toughening of carbon nanotube reinforced alumina nanocomposite fabricated by molecular level mixing process," Scripta Materialia, vol. 53, no. 7, pp. 793-797, 2005.

[19] A. Peigney, F. L. Garcia, C. Estournès, A. Weibel, and C. Laurent, "Toughening and hardening in double-walled carbon nanotube/nanostructured magnesia composites," Carbon, vol. 48, no. 7, pp. 1952-1960, 2010. 

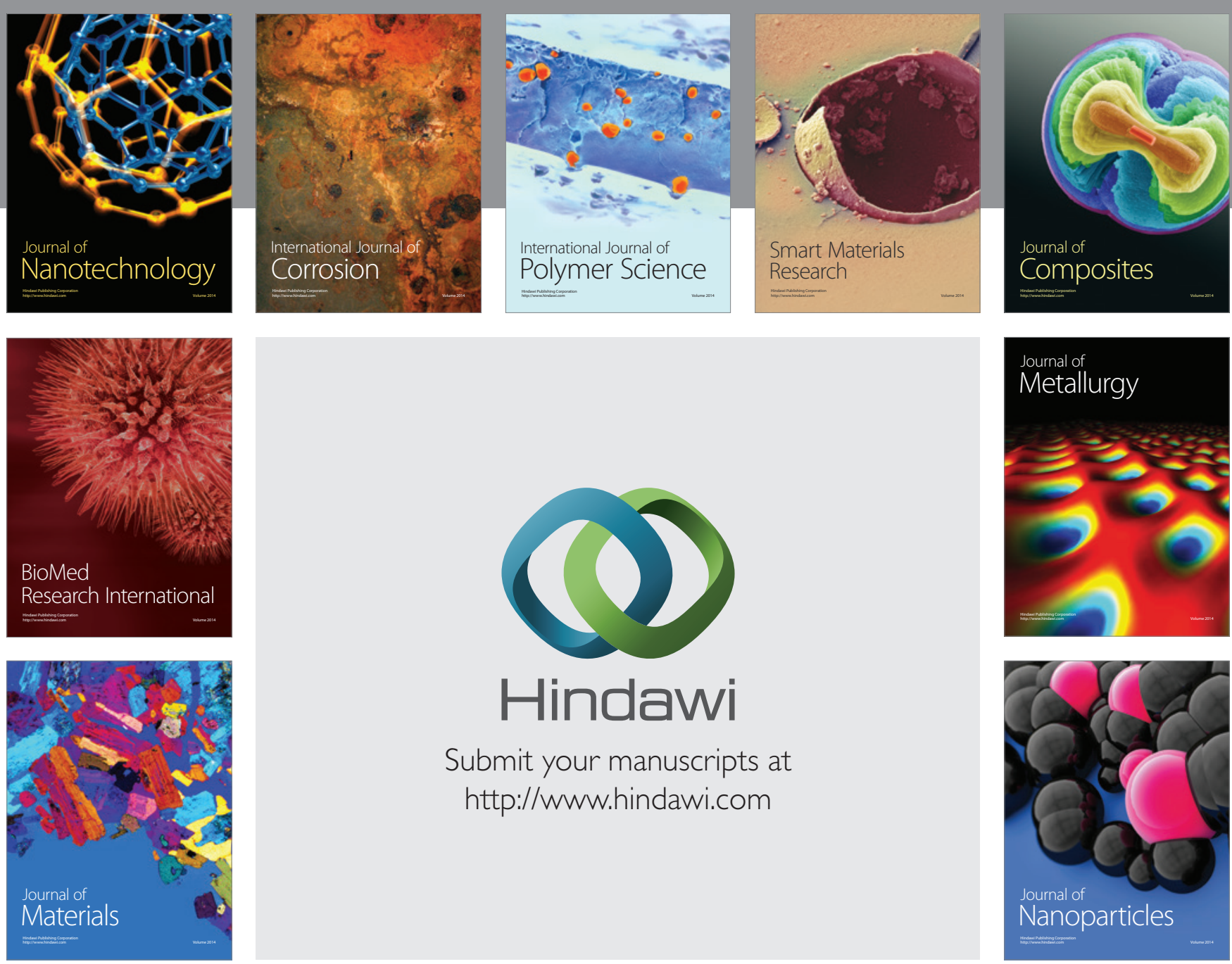

Submit your manuscripts at http://www.hindawi.com
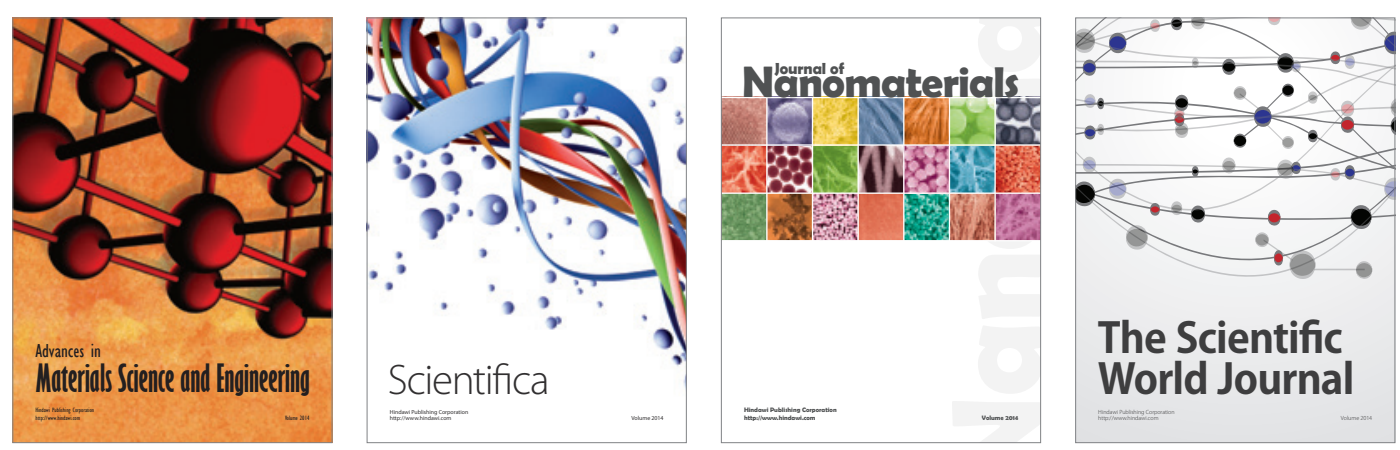

\section{The Scientific World Journal}
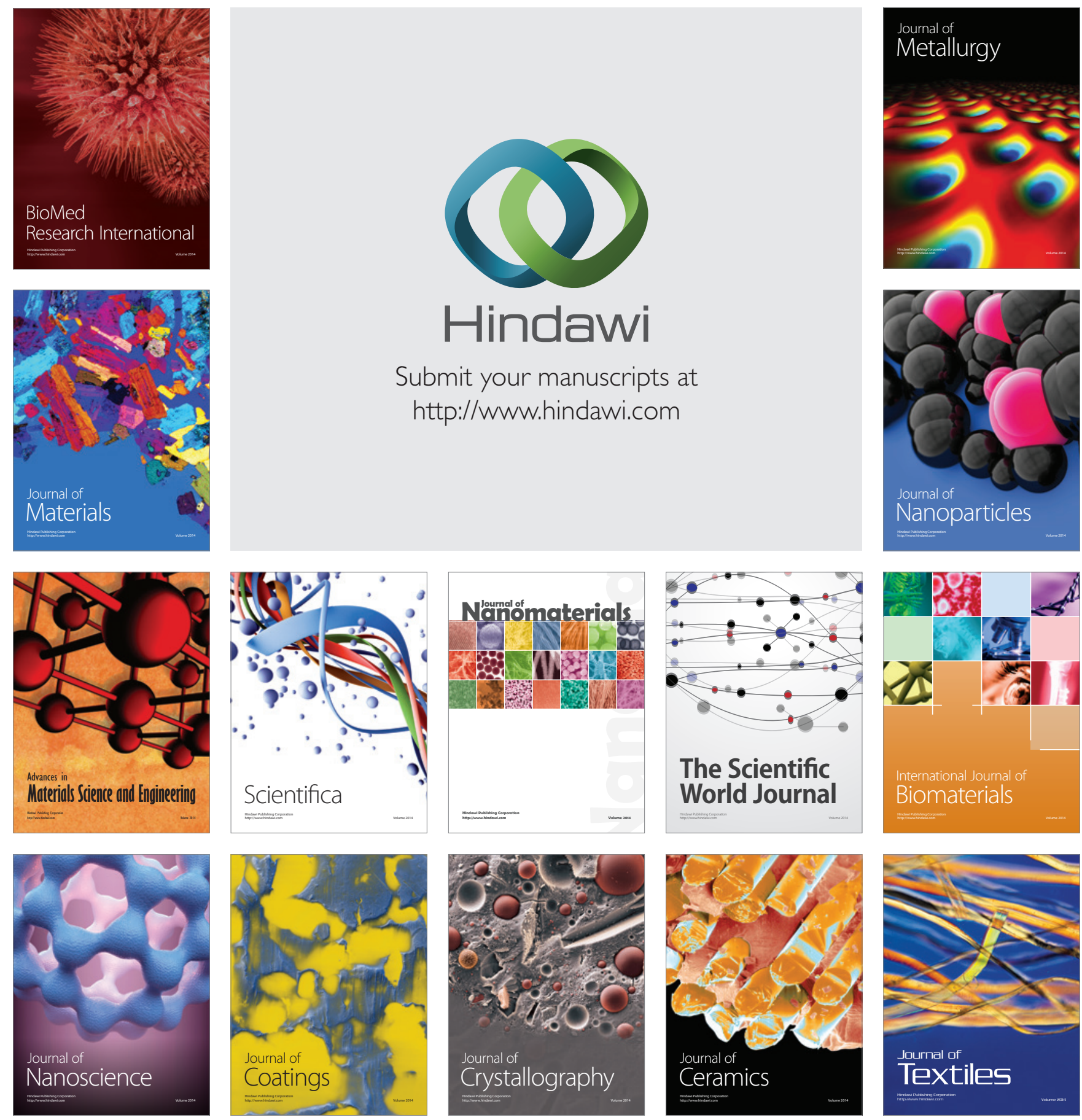